DOI: https://doi.org/10.3126/njdrs.v15i0.31583

\title{
Rural Community Tourism: An Approach toward Sustainable Development Goals
}

\author{
Bharat Prasad Badal, PhD \\ Resource Person, Central Department of Rural Development \\ Ttribhuvan University, Kirtipur, Kathmandu \\ Email for correspondence: bpb222@yahoo.com
}

\begin{abstract}
This paper highlights on Rural Community Tourism (RCT) that can be a new approach to achieve sustainable development goals (SDGs). However, United Nations Development Program and concerned government Agency has yet started working by linking two fundamental tools of Rural Development i.e., Rural Community Development and Rural Tourism. Therefore, to identify the linkages between such tools and for developing new RCT as new approach, the study has been conducted. Methodologically, this study applied library based method for data collection and comparative review analysis method for appraising research issues. Theoretically, this study look at on 17 SDGs and RCT both are developed based on the principles of sustainable development. This study comes up with conclusion that only RCT can link entire 17 sustainable goals with nominal investment. Hence, better to apply RCT, a new approach by federal governments (federation, provincial and local levels) as well as UN development agencies and I/NGOs while planning and implementing 17 SDGs related plans, programs and projects.
\end{abstract}

Key words: Approach, rural community tourism, sustainable development goals

\section{Introduction}

Tourism is one of the fastest-growing economic sectors in the world, currently accounting for the creation of 1 in every 11 jobs and it accounts for 10 percent of world Gross Domestic Product (GDP) (UNWTO \& UNGCN, 2016). Simply love and respect to the visitor can make human life better socially, economically and environmentally. Nepalese culture of peace, love respect everything as god in rural area is a gray land for tourism. Rural Tourism is the business with only social capital. It does not need financial capital, because rural tourism is simply keeping the environment tourist friendly. The people's behavior must be tourist friendly. The follow up of socio-cultural norm "Atithi Debo Bhawa" is enough for the betterment of rural tourism.

Rural Community Tourism (RCT) is a pragmatic approach to attract tourists presenting outstanding social capital of rural community. It is simply a rural community framework for tourists. Serving hospitality, presenting and preserving cultural identical activities - live cultural shows of the rural community from the philosophy of sustainable rural development. Therefore, rural community tourism is a multidimensional approach of poverty reduction of rural people from community led 
tourism. As the main goal of MDG or SDG is to eradicate worst form of poverty. The poverty alleviation is possible from 17 dimensions of 17 Goals of SGD and joining it with rural community tourism also produce 17 ways of job creation by establishing new tourism ventures. We can convert consequences of poverty into tourism product by hospitability and services.

The use of traditional rural buildings for tourism affirmation is considered sustainable when the main reference is made to the protection of the local environment and to encourage tourists to visit the same destination again. Exceptional cultural values can be found in the facilities of traditional architecture, as well as the products of old crafts, through which the local heritage and tradition can be learnt about. This variety of tourist resources and the richness of cultural heritage are especially enriched with exceptional hospitality and cordiality of the locals (Patrovik, et al., 2018). Thus Rural Community Development is optimum utilization of local resources from social, economic, political and environmental perspectives with hospitality to serve the tourists sustainably.

More specifically, rural community tourism is also to promote homestay tourism that has been emerging as a form of sustainable tourism in many rural areas as a community development program in Nepal. The entire activities from the particular location have been integrated as a major component of rural tourism in homestay programs. In general, rural communities or private house owners have been operating homestay programs where guests are offered only basic facilities i.e. normal bed just as the host sleep in their own bed, local food as host normally eat, and unique traditional hospitality with different cultural and natural beauties of particular area. Local cultural activities, traditional lifestyle of host, local tests can be experienced by guests taking part in a homestay program (Lama, 2013). But Rural Community Tourism is a program, a process and a strategy to enhance the living standard of the people by selling the hospitality of natural and cultural heritage of individual and community level. As a program it is a set of instructions in a given environmental mechanism to increase the per capita income of people by setting at least two guest rooms on each household of targeted community. Orientations, motivations, trainings, capital formation and supply of required capital from local cooperatives mobilization will be the input factors. Rural Community Tourism is a communitybased tourism development program, where tourists can have interaction and direct experience of the day-to-day life of the community. Tourists can see and feel local tradition and culture. The concept of homestay addresses the theme of eco-tourism in Nepal. It impacts preliminary on women, local economy, environment, children and the community that shows the effectiveness of the homestay approach. This approach preserves the rural lifestyle, culture and identity. A growing number of locals are operating the homestay program, offering tourists a window into their local culture in areas without hotels (Thapaliya, Rai, Shrestha, Parajuli, \& Pande, 2012). This is the symbol of progressive change.

Village tourism cannot prosper sans the convergence of needs of the affluent and the needy based on the premise of demand driven mechanism because it is a need base concept. Nepal can harness the boon of tourist potentiality rampant at the rural areas where government has pro-poor programs. Community tourism is based on 3 pillars- service, facility and attraction (Sharma, 2012). Interpretation, which means telling the cultural or heritage story is essential. It can be done by video, dramatic performance, wall panels and storytelling. The key to success is to Engage the visitor, allow them the chance to Explore, provide Intrigue and make your story Vibrant. Research shows that the human element in telling the story is most effective (Heneghan, Caslin, Ryan, \& O' Donoghue, 2016). 
The story telling performances like Krishna Charitra dance or drama can be an awesome tourism product.

Till the date Nepal has only "attraction" element of tourism product which is not enough. It's a business so it must be demand driven and private sector upper hand. Tourism is an enterprise where a big business takes place between two parties and along/among a series of stakeholders. A tourist is a thirsty man with lot of money and curiosity. The two parties' interests converse into satisfaction. A triangulation takes place among three elements product-entrepreneur-tourists. Sustainable tourism takes place if home grown resources are used and natural setting is preserved. Promotion of tourism highly depends upon the active participation of private sectors and communities where the role of government becomes facilitation (Sharma, 2012). Ecotourism as a component of the green economy is one of the fastest growing segments of the tourism industry, and focuses on environmental conservation, socioeconomic development and capitalist development. Like other special interest homestay is a community based tourism product that has shown substantial growth in terms of number of visits in recent years.

Homestay accommodation has been practiced in Europe for decades in major cities like Rome and London. In Australia homestay is among international fee paying students. Tourism involves multi-faceted social, cultural, environmental and economic implications. Home-Stay is a micro tourism entrepreneurship. It is a new concept adopted in Nepal. However, lot of enthusiastic groups (communities) and individuals are eager to run this business sans much idea and knowledge. Government lacks a concerted vision, plan, policy, strategy and program. It has to do a lot of homework because it can be an instrument of poverty alleviation strategy. The tourism sector is a key factor in the fight against climate change, since it generates around 5 percent of the total $\mathrm{CO} 2$ released to the atmosphere (UNWTO \& UNGCN, 2016). It is the only solution of current environment and climate change problems.

\section{Objectives}

- To develop a concept to link Sustainable Development Goals (SDGs) with Rural Community Tourism (RCT).

- To identify the linking points between Rural Community Tourism (RCT) with Sustainable Development Goals as a new approach of rural development.

\section{Methodology}

The study has been applied library based method. The information related to research issues are generated through secondary sources of data such as empirical research findings, books, articles and reports. More so, this study has also designed to compare and develop the concepts of RCT and sustainable development goal through comparative review method.

\section{Discussions: Policy Perspective and Empirical Findings}

The vision for tourism expressed in the Government's Vision 2020 and adopted for the National Strategy Plan for Nepal is:

"Tourism is valued as the major contributor to a sustainable Nepal economy, having developed as a safe, exciting and unique destination through conservation and promotion, leading to equitable distribution of tourism benefits and greater harmony in society" 
According to the Tourism Policy 2065, associated with tourism industry service flow guideline 2070 under the clause six, $k a$ Vision and $k h a$ Goals are as below.

The vision of Nepalese tourism sector is to develop nation in one of the safe, beautiful and attractive destination by promotion, development and conservation of natural, ecological biodiversity and manmade cultural heritages. Same law in clause 8 Kha says the project should be focused on rural tourism, inclusion and cooperatives. Thus following Tourism Policy 2065, Tourism Industry Service Flow Guideline 2070 and Homestay Guidelines 2065 the program has been developed.

A sense of community involvement, space, freedom, cleanliness, quality, environmentally sensitive practices and IT facilities are at the core of a rural holiday, all of which add contrast to the urban holiday and ensure authenticity (Heneghan, Caslin, Ryan, \& O’Donoghue, 2016)

According to the finding of a research conducted by Pitambar Sharma, "A thriving or blooming tourism can bring about cross-sectional changes in this country" (Sharma, 2012). Sharma has very succinctly or concisely summarized the potentiality in three words: nature, adventure and culture. With evidences and rich data, Sharma argues that a tourism-led development strategy in Nepal offers several advantages. Tourism can be the basis for the diversification of the economy and a critical source of foreign exchange earnings. Although capital intensive to begin with, it is also an important generator of employment. With sound planning and determination, by 2030 this country will have more to offer to the lay traveler as well as the intrepid adventurer than any comparable area on earth.

In contemporary studies on the development of the international trends in travel industry, rural tourism has raised as its increasing and relevant segment. This type of tourism was recognized by local communities, as well as local municipalities, as an important economic activity that had many manageable challenges and regeneration utilities in rural surroundings. Rural tourism was not strongly based on property development, but it was created largely by revalorizing existing properties and heritage potentials as rural tourist attractions and accommodation facilities. This activity can be developed locally with participation from small businesses to the local municipalities. It frequently provides a base for the local businesses that might not otherwise be in rural communities because of their small populations. Moreover, rural tourism particularly helps both types of small businesses in rural areas (Patrovik, et al., 2018)

\section{Rural Community Tourism: New Approach}

Oxford dictionary defines, Approach is to come nearer to something or someone, to deal with something, a way of doing something and to make advances to especially in order to create a desired result. As a living system, tourism has changed continuously. This change has affected tourism and quite diverse approaches have emerged accordingly. Some of these new approaches are social responsibility, health, sustainability of resources, tourism alternatives, new touristic attractions etc. (Ayazlar \& Ayazlar, 2016). Similarly, rural tourism includes tourism activity itself (accommodation, guesthouse, tourist movement, currently running programs of Governments, provision of basic services and supplementary) - economic activities (mainly agriculture, but also the practice of traditional occupations) and how to party leisure segment, for those who require this type of tourism.

Rural tourism develops in close connection with the local economy, which leads to interdependence between tourism activities and local economy (Barbu, 2013). Specifically, rural tourism is a tool of development of rural livelihood. To uplift the rural livelihood United Nations 
Development Program had advised the Sustainable Development Goals. Simply blending the concept of rural community tourism with sustainable development goals produce a substantial result in rural community on poverty reduction. Simply applying community development programs on rural transformation from tourism perspective is Rural Community Tourism.

Human wants freedom from these smoke, dusts and pollutions of cities but compelled to stay by the necessity of the job or work. The nature of human being is unique because of regular attainment of peace and amusement that is only possible in rural areas. Normally rural areas are those areas with natural beauties, flora and fauna, and pollution free areas. Except few cities Nepal is a rural area or community. We can productify these features of rural community in rural tourism.

Rural tourism dates back to the romanticism movement that began in the late eighteenth century. Romanticism, which was developed as a counter to industrialism, began in the natural world. The first creative tours in rural areas were rurally based on the holiday concept, but modern rural tourism began after the World War II era (Ayazlar \& Ayazlar, 2016). Since then people are attracted toward the nature but Nepal is not being able grab the opportunities.

Rural areas around the world are becoming more innovative with their environment. New opportunities such as; on-farm accommodation, traditional countryside pursuits, education trips, mountaineering, angling and the increasing popularity of kayaking, canoeing and health breaks are helping to generate supplementary income on farms (Heneghan, Caslin, Ryan, \& O’Donoghue, 2016).

Accommodation sector constitutes one of the major components of tourism industry globally out of its popular 4 'As' i.e. Attractions, Accessibility, Accommodation and Ancillary facilities (Shedai, 2011). Accommodation sector, which is also considered as one of the major sub-sectors of tourism industry globally, has a huge potential to generate employment and income through the addition of values within its multiple layers of chains. Tourism accommodation is also one of the determinants of tourist choice for their destination (Shedai, 2011). Therefore, accommodation in tourism plays a vital role which is very easy by the development of community tourism and homestay trainings in every community. It is not necessary to establish hotels but simply empowering local community with the philosophy of AthithiDeboBhawa- Guests are god.

Tourism can be viewed as a space-time convergence between hosts and guests. The emergence of ethnic and cultural tourism implies that tourism also includes interaction and encounter between hosts and guests. Rural tourism provides opportunities to ethnic minorities, indigenous and marginalized people to showcase their culture, customs and heritage. When tourism is introduced culture is commoditized. Culture will be preserved by the commercialization and productification of culture. Regarding this matter, the scholars are divided into two camps. Accordingly, one school of thought clearly advocates that tourism brings cultural transformation whereas the other camp proposes that commoditization will not effect on the culture of host population. The economic and socio- cultural impact of tourism is dealt along with the income generation and change in gender roles (Kunwar \& Pandey, 2015). Business with vision will develop the culture. If we show our cultural products to the guests and began to earn means it is both - earning and preserving. So we shouldfocus on Janajati and marginalized women as our targeted group of beneficiaries. These people will learn, earn, and preserve the culture. 
Rural areas are experiencing huge changes and challenges such as population decline and reduced incomes. Many farmers are considering rural tourism as an opportunity to generate income and overcome the challenges facing farming by providing accommodation and/or activities for tourists (Heneghan, Caslin, Ryan, \& O’Donoghue, 2016).

Homestay tourism has been practiced in Nepal since time immemorial, as tourists are regarded as Atithi Devo Bhava (Guests are God), in the Nepali society. Due to countless ethnic community with mosaic of cultures, attributed to diverse social practices, has immense possibility for the enthusiasts to enjoy homestay tourism in Nepal. Village/community tourism is a meso tourism concept evolved lately in the tourism world (Sharma, 2012). Nepal can be a model destination of it for she possesses multifaceted potentialities. Natural gifts, man made heritages ethno-cultural richness, innocent social setting and hospitality and many more unexplored treasures are dreams for connoisseurs of tourism (Sharma, 2012). Diverting international tourists to rural destinations of Nepal is one of the tourism policies of the government (Lama, 2013). The conducive policy environment has to create rural tourism environment and facilitate communities and private sectors to carry out the tourism business. There are innumerable temporary challenges which can be resolve with appropriate software as well as hardware programs. Nepalese tourism market is big and it has unexhausted products. The concerned stakeholders have to exploit and reap the products. However, most of the products have yet to be explored. Brain drain, youth out migration, unemployment and underemployment problems can be mitigated with charting out a national policy (Sharma, 2012).

In New Zealand and Germany rural tourism used to be called farm stay many years back (Kunwar \& Pandey, 2015). Nepalese home stay can be expanded up to farm stay tourism. It is very useful on the development of women, cooperatives, enterprises, and so on from tourism perspective in such beautiful rural areas of Nepal. Tourism is itself a type of community based business that accommodates visitors in a village with a local family by enabling the visitors to discover local life, nature and culture. Community based homestay or farm stay tourism is closely related to nature, culture, and local customs. It is intended to attract those tourists who are really interested about sociology, anthropology, culture, population, development studies, international relations, tourism, and management of specified locality and culture.

Tourism can contribute to promote peaceful and inclusive societies, to promote the protection of the fundamental rights of local communities and to fight against corruption as well because it fosters tolerance and understanding between different cultures and serves as a livelihood for local communities, while preventing violence and consolidating peace in societies that have experienced recent conflicts (UNWTO \& UNGCN, 2016). So rural tourism must be linked with rural community development. The perfect blend of rural tourism with community development will be Rural Community Tourism Development Program.

\section{Linkage between RCT and Sustainable Development Goals: The Major Activities}

The major activities to tie up the SDG with RCT can be handled from local governments. Developing a rural community tourism to reduce poverty in the area in rural municipalities can bring the tremendous change in rural human life. The major activities are collected and summarized below (Table 1). 
Table 1. The Major Activities for Developing RCT

\begin{tabular}{ll}
\hline Categories & Activities \\
Preliminary Activities & 1. Concept development \\
2. Proposal development \\
3. Meetings with funding agencies \\
4. Official agreements \\
5. Office management \\
6. Staffs recruitment \\
7. Community assessments \\
8. Reviews and planning \\
9. Orientations \\
10. Trainings \\
11. TOTs \\
12. Motivations \\
13. Career Planning in tourism \\
14. Capital formation training \\
15. Cooperatives' trainings \\
16. Household survey \\
17. Feasibility study \\
18. Construction of Guest Rooms and kitchen \\
19. Community cultural program trainings \\
20. Tests \\
21. Website / blog of each homestay \\
22. Brochure \\
23. Development of Token of Love \\
24. Official visits \\
25. Educational tours \\
26. Radio /television Zingales \\
27. Publicity /documentary \\
28. Workshops/ Seminars \\
Marketing and Promotion
\end{tabular}

(Developed by the Researcher, 2018)

Besides, the lists of important assignments or responsibilities of local authorities ${ }^{1}$ are to be employed are also presented below:
a. Take the guidelines, TOT and trainings from office
b. Read policies, plans, programs, laws, etc. of Tourism
c. Visit the respective wards and conduct the meeting with ward members
d. Finalize the home stay development settlement
e. Form Homestay Development Committee of 19 or 21 people from the community to make homestays
f. Find the tourism business potentialities on the community
1 The list has been prepared by the experiences shared by the elected representatives and concerned stakeholders of Mahalaxmi Municipality of Lalitpur District in 2017.


g. Make or Manage a community training center

h. Develop sustainable tourism business plans and proposals

i. Train (Hospitality, culinary and tourism) the community members

j. Motivate the community members to start tourism business

k. Accountability trainings

1. Entrepreneurship training

m. Capital formation training

n. Cooperative operation training

o. Meeting with local cooperatives

p. Finalize the homestay development proposals of entire members

q. Help, encourage, train and Motivate each member to start a home stay

r. Make a home stay at least with 20 beds in a settlement of a ward

s. Prepare and submit daily, weekly, and monthly achievement report

t. Assist the sustainable operation of tourism projects of community and wards

u. Make a route and link entire tourism destinations of Municipality

v. Conduct weekly meeting with Members

w. Marketing and publicity

$\mathrm{x}$. Online Marketing and social media mobilization

y. Book/ Documentary

(PRA, 2017)

\section{Sustainable Development Goals in Rural Community Tourism}

Tourism is one of the largest and fastest-growing economic sectors of the world, accounting for 10 percent of world GDP and 7 percent of total international exports in 2015 (UNWTO \& UNGCN, 2016). Tourism is a great example for conveying to enterprises that sustainable development is a business driver so in order for the sector to continue to grow sustainably and provide greater benefits to society it is essential to operate in a responsible manner and in the context of Sustainable Development Goals (SDGs) (UNWTO \& UNGCN, 2016). In September 2000, the 189 member countries of the United Nations signed a global alliance that materialized in the establishment of the Millennium Development Goals (MDGs).

Among the goals set were to eradicate extreme poverty and world hunger, achieve universal primary education, ensure environmental sustainability and develop a global partnership for development. The 15 years of work on the MDGs revealed major difficulties for their achievement, such as: the importance of identifying sources of funding, the establishment of appropriate indicators to measure progress, and the lack of clarity about the role of certain actors in achieving the agenda, such as civil society and the private sector. Finally, on 25 September 2015, the United Nations General Assembly approved the 2030 Agenda for Sustainable Development and with it, the Sustainable Development Goals, a framework comprising 17 goals and 169 targets, through which States, civil society and the private sector can guide and measure their contributions to sustainable development out to 2030 (UNWTO \& UNDP, 2017).

Nepal's tourism infrastructures is improving. The country has 1,073 tourist standard hotels, world class trekking trails, and 957 cultural heritage tourist attractions. In 2015, 790,000 tourists 
visited Nepal staying on an average 13 days and spending \$ 69 per day. The government aims to increase tourist arrivals to 1.34 million and increase length of stay to 15 days by 2020 (NPC, 2017). Nepal, on the other hand, expects that the enhancement of infrastructure (related to SDG 9) will lead to increased tourism activity in the country. In addition, enhanced partnerships (related to SDG 17) and the preservation of marine and terrestrial ecosystems (related to SDGs 14 and 15), for instance, can also help tourism to flourish. Effective partnerships can spur investment in the sector, while the green and blue economy can both promote SMEs in tourism, particularly in rural and coastal areas. Given the integrated nature of the SDGs, the spill-over effects that result from the various activities towards the SDGs can and should be taken advantage of by the tourism sector (UNWTO \& UNDP, 2017). Tourism can contribute directly or indirectly to all these Goals. Specifically, tourism appears in the targets of Goals 8, 12 and 14, which relate, respectively, to inclusive and sustainable economic development, sustainable consumption and production, and sustainable use of oceans and marine resources (UNWTO \& UNGCN, 2016). So Develop and implement tools to monitor sustainable development impacts for sustainable tourism which creates jobs, promotes local culture and products. The tourism industry can give access to decent work opportunities, particularly in developing countries. Promoting smarter and greener cities can attract tourists and also benefit residents. Reducing greenhouse gas emissions to guarantee the sustainability of the tourism sector and preserve destinations benefiting both tourists and local communities.

Forests are not only an asset for environmental protection but also have huge potential for job creation, income generation and tourism promotion. Nepal has not fully used the potential of its forest resources. But as mountain resources are so crucial for Nepal's fresh water resources, hydropower, livelihood, agriculture, adventure tourism, and environment protection, some specific targets could be set and indicators developed for this goal (NPC, 2015). Nepal governments of every level must act in accordance with the philosophy of hospitality and sustainable development to achieve desired goal.

\section{Conclusion}

There is great potential for tourism policy makers to maximize the sector's contribution to the SDGs while harnessing the opportunities that derive from the overall progress towards the SDGs. In conclusion the Rural Community Tourism will be a platform to achieve the sustainable development goals. Only tourism can easily link entire 17 sustainable goals with nominal investment. Theoretically sustainable goals and rural community tourism both are based on the principles of sustainable development. Those 17 goals are 17 links of each other because urban related or sea related issues are also linked with environment and pollutions. So it is recommended to UN agencies, NGOs, INGOs, Government officials and policy makers while planning and implementing the SDG related plans and programs must link with rural community tourism. If a village equipped with community homestay like programs to enhance hospitality, love and peace with clean and hygienic environment, it does not take long time to achieve the sustainable goals. Of course there are many jargons related to rural tourism like "Agro Tourism, Eco Tourism, Sustainable Tourism, Religious Tourism, Adventure tourism, Health tourism, sports tourism, business tourism, nature tourism, pro poor tourism, cultural tourism" etc. are simply the dimensions of Rural Community Tourism. Summations of entire such tourism to uplift the living standard of locals and enriching the happiness of visitors is Rural Community Tourism. 


\section{References}

Ayazlar, G., \& Ayazlar, R. (2016). Rural Tourism: A Conceptual Approach. In N. H. Mihaela Dinu, Tourism, Environment and Sustainability (pp. 167- 184). Bulgeria, Sophia: St. Kliment Ohridski University Press.

Barbu, I. (2013). Approches to the concept of Rural Tourism. Arad, Romania: Aurel Vlaicu University

Heneghan, M., Caslin, B., Ryan, M., \& O’Donoghue, C. (2016). Rural Tourism. Teagasc, Oak Park, Carlow, Ireland: Agriculture and food Development Authority.

Kunwar, R. R., \& Pandey, C. (2015). Tamang heritage trail:A study of Gatlang village in Rasuwa district of Nepal. Journal of Tourism and Hospitality 6, 01-40.

Lama, M. (2013). Community Homestay Programmes as a Form of Sustainable Tourism Development in Nepal. Kokkola, Finland: Centria University of Applied Sciences .

NPC (2015). National Planning Commission, 2015: Sustainable Development Goals, 2016-2030. Kathmandu, Nepal: National (Preliminary) Report. Government of Nepal, National Planning Commission, .

NPC (2017). National Review of Sustainable Development Goals. Kathmandu, Nepal: National Planning Commission.

Patrovik, M., Vujko, A., Gajic, T., Vukovic, D., Radovanovic, D., Jovanovic, J., \& Vukovik, N. (2018). Tourism as an Approach to Sustainable Rural Development in Post-Socialist Countries: A Comparative Study of Serbia and Slovenia. Sustainability , 10, 54, 1-14.

Sharma, P. (2012). Prospects and challanges of Homestay in Nepal. Homestay Tourism in Nepal: Opportunities and Challenges (pp. 39-50). Kathmandu: Alumni Network for Mountain Development (ANMD) Nepal and Tourism Board Nepal.

Shedai, R. (2011). Tourist accomodation facilities of major tourist area of Nepal. Nepal Tourism and Development Review 1, 102-123.

Thapaliya, M., Rai, G. S., Shrestha, A., Parajuli, B., \& Pande, O. (2012). Homestay:Assesment in Lawng Ghalel. Nepal Tourism and Development Review 2, 105-140.

UNWTO \& UNDP. (2017). Tourism and the Sustainable Development Goals - Journey to 2030. Madrid: UNWTO and UNDP.

UNWTO \& UNGCN. (2016). The tourism sector and the Sustainable Development Goals-Responsible tourism, a global commitment . Madrid: World Tourism Organization (UNWTO) and United Nations Global Compact Network Spain. 